\title{
Clinical Value of High Mobility Group Box 1 and the Receptor for Advanced Glycation End- products in Head and Neck Cancer: A Systematic Review
}

\author{
Austin Nguyen $^{1}$ Sheila Bhavsar ${ }^{1} \quad$ Erinn Riley $^{1}$ Gabriel Caponetti ${ }^{2} \quad$ Devendra Agrawal $^{1}$ \\ ${ }^{1}$ Department of Clinical and Translational Science, Creighton \\ University School of Medicine, Omaha, Nebraska, United States \\ ${ }^{2}$ Department of Pathology, Creighton University School of Medicine, \\ Omaha, Nebraska, United States

\begin{abstract}
Address for correspondence Devendra Agrawal, PhD, Department of Clinical and Translational Science, Creighton University School of Medicine, 2500 California Plaza, Omaha, NE 68172, United States (e-mail: DevendraAgrawal@creighton.edu).
\end{abstract}

Int Arch Otorhinolaryngol 2016;20:382-389.

\begin{abstract}
Introduction High mobility group box 1 is a versatile protein involved in gene transcription, extracellular signaling, and response to inflammation. Extracellularly, high mobility group box 1 binds to several receptors, notably the receptor for advanced glycation end-products. Expression of high mobility group box 1 and the receptor for advanced glycation end-products has been described in many cancers.

Objectives To systematically review the available literature using PubMed and Web of Science to evaluate the clinical value of high mobility group box 1 and the receptor for advanced glycation end-products in head and neck squamous cell carcinomas.

Data synthesis A total of eleven studies were included in this review. High mobility group box 1 overexpression is associated with poor prognosis and many clinical and

Keywords

- HMGB1 protein

- advanced glycosylation end product-specific receptor

- head and neck neoplasms pathological characteristics of head and neck squamous cell carcinomas patients. Additionally, the receptor for advanced glycation end-products demonstrates potential value as a clinical indicator of tumor angiogenesis and advanced staging. In diagnosis, high mobility group box 1 demonstrates low sensitivity.

Conclusion High mobility group box 1 and the receptor for advanced glycation endproducts are associated with clinical and pathological characteristics of head and neck squamous cell carcinomas. Further investigation of the prognostic and diagnostic value of these molecules is warranted.
\end{abstract}

\section{Introduction}

The high mobility group box 1 protein (HMGB1) is a highly conserved and highly versatile nuclear and extracellular protein found in eukaryotic cells. HMGB1 is a non-histone, chromosomal protein that has been implicated in a variety of biologically important processes, including transcription, DNA repair, and extracellular signaling. ${ }^{1}$ Structurally, HMGB1 consists of 215-amino acid polypeptide organized into two DNA-binding domains (termed A-box and B-box)

received

January 20, 2016

accepted

February 28, 2016

published online

April 19, 2016
DOI http://dx.doi.org/ 10.1055/s-0036-1583168. ISSN $1809-9777$. and a negatively charged C-terminal tail. 2,3 Functionally, HMGB1 appears to have two distinct roles in cellular systems. In the intracellular milieu, HMGB1 localizes to the nucleus and non-specifically binds to the minor groove of DNA, facilitates the assembly of DNA-binding proteins, and is involved in regulating gene transcription. ${ }^{4,5}$

Following release into the extracellular space, HMGB1 acts as a pro-inflammatory cytokine that is secreted by activated monocytes, macrophages, and natural killer (NK) cells. It is also passively secreted by necrotic cells and is, therefore,

Copyright $(2016$ by Thieme Publicações License terms Ltda, Rio de Janeiro, Brazil

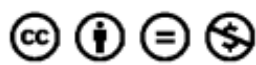


referred as an optimal marker of necrosis. ${ }^{6,7}$ It is involved in the mediation of neurite outgrowth, smooth muscle cell chemotaxis, mesoangioblast migration and proliferation, and tumor growth and metastasis. ${ }^{8-10}$ The extracellular HMGB1 binds to several cell surface receptors, including the Receptor for Advanced Glycation End-products (RAGE) and the Triggering Receptor Expressed on Myeloid cells 1 (TREM-1). ${ }^{11,12}$

RAGE is a transmembrane protein that belongs to the immunoglobulin superfamily. It can bind to advanced glycation end-products, the resulting product of nonenzymatic glycation. RAGE is mostly stimulated by cellular stress, such as inflammation and is therefore found to be overexpressed in many diseases, such as different cancers. ${ }^{13}$ In certain cells, HMGB1 and its receptor, RAGE, co-localize on the cell surface. Authors have reported that HMGB1 binding to RAGE may activate signaling pathways, such as Ras/MAKP, PI3K/Akt, NF-kB, which leads to overexpression of genes and the change in the biological behavior of tumor cells. ${ }^{14}$ Previous studies have found that HMGB1 and RAGE play important roles in the development, growth, and metastasis of multiple tumors. ${ }^{15,16}$

The RAGE-HMGB1 interaction can diminish host anticancer immunity by inducing apoptosis in antigenpresenting dendritic cells and reprogram immune cells by promoting tumor-infiltrating $\mathrm{T}$ cell-expressed lymphotoxin $\mathrm{a} 1 \mathrm{~b} 2$, which leads to the recruitment of $\mathrm{CD} 11 \mathrm{~b}^{+} \mathrm{F} 4$ / $80^{+}$macrophages (tumor-associated macrophages, TAMs) into the tumor for its promotion ( $\mathbf{- \text { Fig. }} \mathbf{1}$ ) by providing growth factors and supporting angiogenesis. ${ }^{17}$ Furthermore, HMGB1 released from necrotic cancer cells treated with chemotherapy enhances regrowth and metastasis of remnant cancer cells in a RAGE-dependent manner. ${ }^{18,19}$ Therefore, blocking the HMGB1-RAGE system may increase the effectiveness of chemotherapy. ${ }^{17}$ In fact, specialists have used soluble RAGE (sRAGE) to prevent the HMGB1RAGE signaling from occurring in animal tumor models by acting as a decoy receptor. ${ }^{20}$

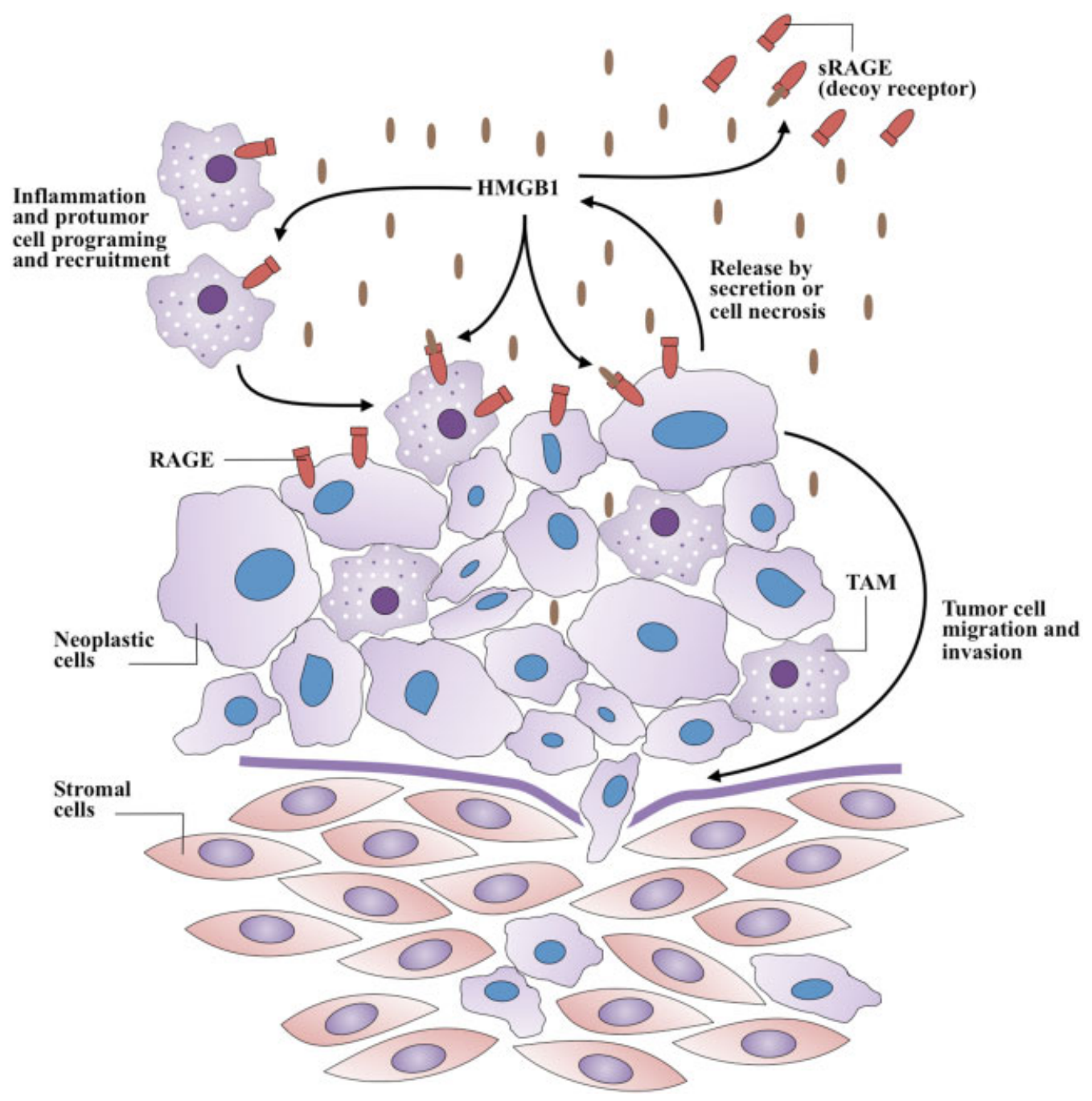

Fig. 1 A generalized model of HMGB1 and RAGE involvement in cancer progression. Whether released by secretion or necrosis, extracellular HMGB1 acts as a proinflammatory cytokine. Additionally, HMGB1 may reprogram immune cells by supporting recruitment of tumor-associated macrophages (TAM) that promote tumor progression. Soluble RAGE (SRAGE) acts as a decoy receptor by binding HMGB1 without subsequent signaling. 
In comparison to RAGE, HMGB1 has been more extensively studied in various cancers. HMGB1 expression appears to be associated with many different tumor types. ${ }^{21-24}$ In addition, the association of HMGB1 overexpression and poor prognosis has been reported in patients with various types of cancers. ${ }^{25-29}$ To our knowledge, however, a systematic evaluation of the clinical value of HMGB1 and RAGE in head and neck squamous cell carcinoma (HNSCC) has not been performed to date.

HNSCC, which consists of several different subtypes, is the sixth most common malignancy in the world and the most common cause of cancer-related death in South Asia. ${ }^{30}$ Despite aggressive treatment approaches, prognosis of patients with HNSCC is quite poor. Due to the poor outcome, it is of particularly high interest to identify any additional biomarkers that allow early detection or implicate prognosis of HNSCC. In this article, we systematically review the available literature regarding HMGB1 and RAGE in HNSCC and evaluate their potential clinical value.

\section{Review of Literature}

We performed a systematic search of the PubMed Database (through July 2015) of the National Library of Medicine using the following Medical Subject Headings: HMGB1 protein, advanced glycation end-product receptor, neoplasm, and head and neck neoplasms. The articles included discussed original research on the clinical value of HMGB1 or RAGE, including prognostic and diagnostic concordance, in head and neck neoplasms. We cross-referenced the search results with the Web of Science database, using the same terms. We excluded articles based on the following criteria: not written in English, conference abstract, and not performed on primary human subjects/specimens.

An initial search of PubMed and Web of Science retrieved 421 articles (-Fig. 2). After reviewing titles and abstracts, excluding non-English articles and conference abstracts, 16 studies remained as potential candidates for inclusion. Full text review excluded five studies due to presentation of data irrelevant to the present topics. Ultimately, 11 studies were included in this systematic review, encompassing a total of 2,098 patients (-Table 1). Examination of HMGB1 and/or RAGE was predominantly performed in sectioned tissue, whether frozen (one study) or formalin-fixed and embedded in paraffin (7 studies). Four studies investigated expression levels in serum/blood. Studies in the squamous cell carcinoma (SCC) investigated the following malignancy types: general

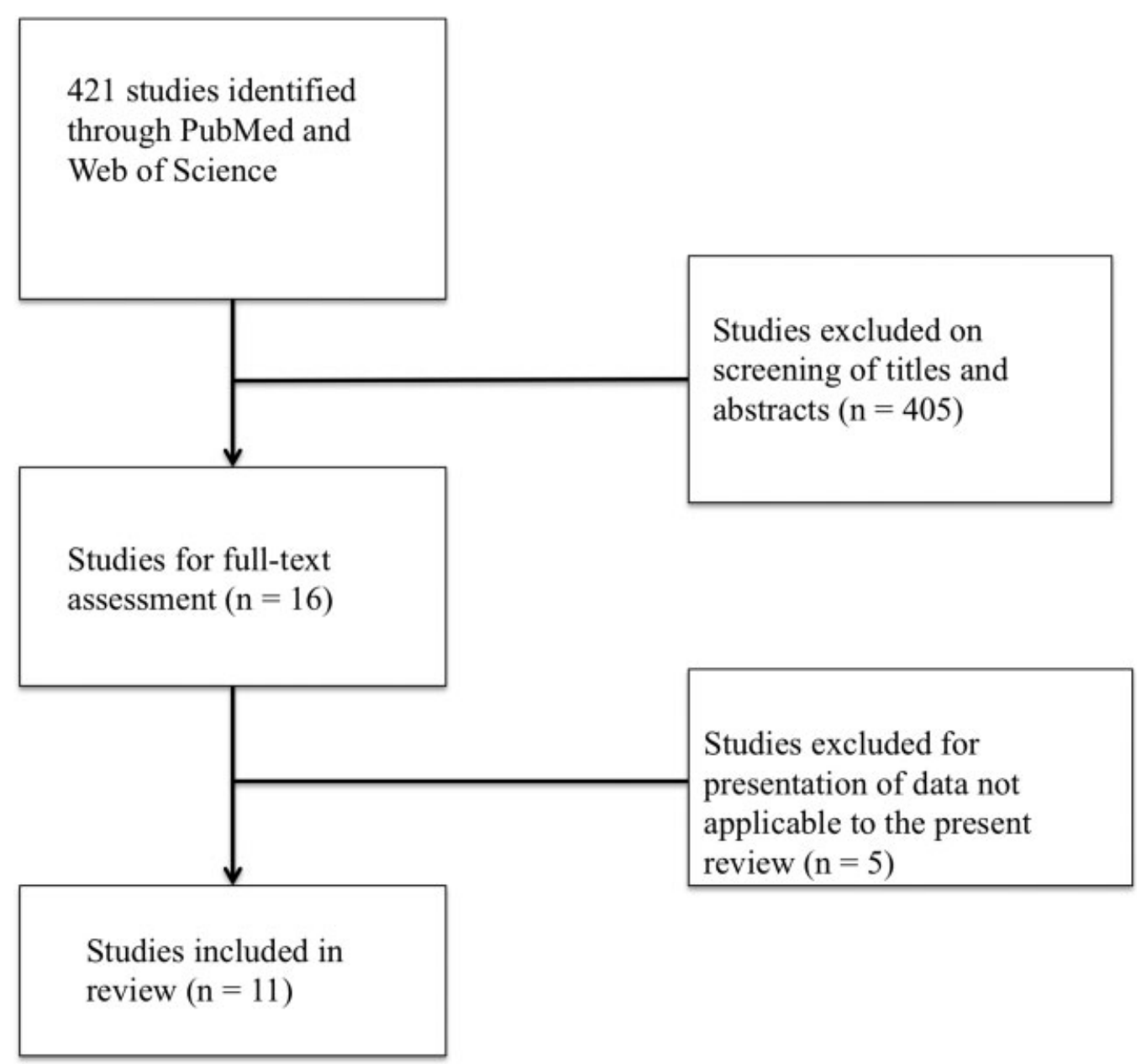

Fig. 2 Systematic search of PubMed and the Web of Science returned 421 total studies. After review of titles, abstracts, and full-text, 11 studies were included in this review. 
Table 1 Study design and population characteristics

\begin{tabular}{|c|c|c|c|c|c|c|c|}
\hline Study & Malignancy & Sample type & $\begin{array}{l}\mathrm{N} \\
\text { (total) }\end{array}$ & $\begin{array}{l}\mathrm{N} \\
\text { (cancer) }\end{array}$ & $\begin{array}{l}\text { Age, } \\
\text { mean/median } \\
\text { (range) }\end{array}$ & $\begin{array}{l}\text { Sex, } \\
\text { M:F }\end{array}$ & Patient notes \\
\hline Sasahira et al $^{31}$ & OSCC & FFPE tissue & 20 & 20 & $69.1(41-83)$ & $10: 10$ & - \\
\hline Sasahira et al $^{35}$ & OSCC & FFPE tissue & 62 & 62 & - & $35: 27$ & Treatment naive \\
\hline Wu et $\mathrm{al}^{36}$ & NPC & FFPE tissue & 166 & 166 & $47.7(13-74)$ & $133: 33$ & Treatment naive \\
\hline Landesberg et $\mathrm{al}^{32}$ & OSCC & FFPE tissue & 50 & 38 & $\begin{array}{l}\text { A: } 69(28-92) . \\
\text { B: } 72(51-88) . \\
\text { C: } 66(55-88) .\end{array}$ & $\begin{array}{l}\mathrm{A}: 4: 7 \\
\mathrm{~B}: 7: 7 \\
\mathrm{C}: 6: 2^{*}\end{array}$ & $\begin{array}{l}\text { A: Well-differentiated tumor } \\
\text { B: Moderately-differentiated } \\
\text { tumor } \\
\text { C: Poorly-differentiated tumor }\end{array}$ \\
\hline Tsuji et al $^{33}$ & NPC & FFPE tissue & 42 & 42 & - & - & - \\
\hline Liu et $\mathrm{al}^{37}$ & HNSCC & FFPE tissue & 103 & 103 & $57.86(27-80)$ & $99: 4$ & - \\
\hline Wild et $\mathrm{al}^{38}$ & HNSCC & $\begin{array}{l}\text { Serum and } \\
\text { frozen tissue }\end{array}$ & 52 & 35 & $64 \pm 10^{*}$ & $29: 6^{*}$ & Treatment naive \\
\hline Qiu et $\mathrm{al}^{39}$ & LSCC & Serum & 121 & 71 & $54.5 \pm 14.0^{*}$ & $54: 17^{*}$ & Treatment naive \\
\hline Hanakawa et al ${ }^{40}$ & Tongue SCC & FFPE tissue & 26 & 26 & $69(29-87)$ & $15: 11$ & Treatment naive \\
\hline Supic et $\mathrm{al}^{41}$ & OSCC & $\begin{array}{l}\text { Tumor tissue } \\
\text { (unspecified) } \\
\text { or blood } \\
\text { (controls) }\end{array}$ & 246 & 93 & $58(36-80)^{*}$ & $69: 24^{*}$ & $\begin{array}{l}\text { All received primary surgery } \\
\text { followed by radiotherapy. } \\
24 \text { received neoadjuvant } \\
\text { cisplatin/5-fluorouracil } \\
\text { chemotherapy. }\end{array}$ \\
\hline Su et $\mathrm{al}^{34}$ & OSCC & Blood & 1210 & 618 & $54.29 \pm 11.28^{*}$ & $596: 22^{*}$ & - \\
\hline
\end{tabular}

Abbreviations: FFPE, formalin-fixed paraffin-embedded; HNSCC, head and neck squamous cell carcinoma; LSCC, laryngeal squamous cell carcinoma; NPC, nasopharyngeal carcinoma; OSCC, oral squamous cell carcinoma; SCC, squamous cell carcinoma.

*Does not include controls.

head and neck SCC (HNSCC, 2 studies), oral SCC (OSCC, 6 studies, including one study specifically on tongue SCC), nasopharyngeal carcinoma (2 studies), and SCC of the larynx (LSCC, 1 study). Of these, five studies indicated their included patients to be treatment naive. The study populations were between $50.0 \%$ and $96.3 \%$ male, with a mean/median age of 47.7 to 69.1 years.

\section{The Receptor for Advanced Glycation End-products}

Four studies evaluated RAGE in head and neck cancer patients $^{31-34}$ (-Table 2). The earliest study to be included ${ }^{31}$ analyzed samples from 20 patients with OSCC. The study compared expression of RAGE with angiogenesis and lymphangiogenesis, evaluated by microvessel density and lymph vessel density. A significant positive correlation was found between RAGE concentration and microvessel density ( $p=0.0123$ ), but not between RAGE and lymph vessel density. Additionally, RAGE expression was significantly associated with concentration of vascular endothelial growth factor (VEGF; $p=0.0344$ ). The only clinic pathological factor to be significantly associated with RAGE expression was T-classification, with an elevated level seen in T3T4 classifications compared with T1-T2 $(p=0.0408)$.

In a study involving 38 OSCC cases, Landesberg et al ${ }^{32}$ observed RAGE to be associated with tumor differentiation $(p<0.05)$. RAGE positivity was detected in $100 \%$ of welldifferentiated OSCC, $75 \%$ of well-to-moderately differentiated OSCC, $33 \%$ of moderately differentiated OSCC, $14 \%$ of moderate-to-poorly differentiated OSCC, and $0 \%$ of poorly differentiated OSCC. Additionally, RAGE expression trended toward decreasing staining intensity with less tumor differentiation.
The most recent and largest study ${ }^{34}$ included 618 OSCC patients. Blood was collected and analyzed for RAGE gene polymorphism. Five polymorphisms of the RAGE gene were assessed: $-374 \mathrm{~T}>\mathrm{A}(\mathrm{rs} 1800624),-429 \mathrm{~T}>\mathrm{C}(\mathrm{rs} 1800625)$, 1704G > T (rs184003), Gly82Ser (rs2070600), and a 63-bp deletion allele $(-407$ to -345$)$. The heterozygous $-429 \mathrm{~T}>\mathrm{C}$ genotype was found to be significantly associated with an increased incidence of oral cancer [odds ratio (OR), 1.870; 95\% confidence interval (CI), 1.323 to 2.644], stage III/IV tumors (OR, 1.736; 95\% CI, 1.126 to 2.677), and large tumor size (OR, 1.644; $95 \%$ CI, 1.083 to 2.493 ). None of the other polymorphisms were found to be significantly associated with incidence or clinical status of OSCC.

Lastly, the clinical value of RAGE was also evaluated in nasopharyngeal carcinoma. ${ }^{33}$ Analysis of 42 nasopharyngeal carcinoma specimens demonstrated expression of RAGE to be associated with tumor microvessel density $(p=0.0049)$. Additionally, RAGE expression was significantly higher in cases with lymph node metastasis (N1-3 classification), when compared with that of lymph node metastasis-negative (N0) cases $(p=0.0005)$.

\section{Evaluation of High Mobility Group Box 1}

We found seven studies that investigated the clinical role of HMGB1 in head and neck cancers ${ }^{35-41}$ ( - Table 2). Of these, only one study assessed the diagnostic value of HMGB1 $1{ }^{39}$ Using the cutoff of $4.80 \mathrm{ng} / \mathrm{mL}$, serum HMGB1 was $42.0 \%$ sensitive and $88.3 \%$ specific (positive predictive value of $52.9 \%$ ) for the diagnosis of laryngeal SCC. However, high serum HMGB1 was significantly associated with $\mathrm{T}$ classification $(p=0.005), \mathrm{N}$ 
Table 2 Clinical value of HMGB1 and RAGE

\begin{tabular}{|c|c|c|c|}
\hline Study & HMGB1 or RAGE & Assay & Clinic pathological characteristics or prognosis \\
\hline Sasahira et al ${ }^{31}$ & RAGE (OSCC) & IHC and ELISA & $\begin{array}{l}\text { - Lower in T1-T2 stages than T3-T4 }(p=0.0408) \text {. } \\
\text { - Correlated with MVD }(p=0.0123) \text { and VEGF expression } \\
(p=0.0344) \text {. } \\
\text { - No correlation with N stage, age, sex, histological } \\
\text { differentiation, LVD. }\end{array}$ \\
\hline Sasahira et al $^{35}$ & HMGB1 (OSCC) & $\mathrm{IHC}$ & $\begin{array}{l}\text { - High expression in cancer cell nuclei and nodal metastatic } \\
\text { foci. } \\
\text { - Correlated with VEGF-C and VEGF-D expression }(p<0.001)\end{array}$ \\
\hline Wu et $\mathrm{al}^{36}$ & HMGB1 (NPC) & $\mathrm{IHC}$ & $\begin{array}{l}\text { - Detected in } 53.6 \% \text { of cases, higher in malignant tissue. } \\
\text { - Correlated with T classification }(p=0.01) \text {, N classification } \\
(p=0.003) \text {, distant metastasis }(p=0.046) \text {, clinical stage } \\
(p<0.001) \text {, initial radiotherapy response }(p=0.034) \text {, } \\
\text { overall survival }(p<0.001) \text {, and disease-free survival } \\
(p<0.001) \text {. }\end{array}$ \\
\hline Landesberg et $\mathrm{al}^{32}$ & RAGE (OSCC) & $\begin{array}{l}\text { IHC and } \\
\text { Western blot }\end{array}$ & $\begin{array}{l}\text { - Expression was significantly different by tumor differentiation } \\
(p<0.05) \text { : } 100 \% \text { of well-differentiated, } 75 \% \text { of well-to-mod- } \\
\text { erately differentiated, } 14 \% \text { of moderate-to-poorly differenti- } \\
\text { ated, } 0 \% \text { of poorly differentiated. } \\
\text { - RAGE was highest in normal tissue and trended toward } \\
\text { decreased levels with less tumor differentiation. }\end{array}$ \\
\hline Tsuji et al $^{33}$ & RAGE (NPC) & $\mathrm{IHC}$ & $\begin{array}{l}\text { - Tumor expression correlated with MVD }(p=0.0049) \text {, } \\
\text { suggestive of the important role of RAGE in angiogenesis. } \\
\text { - Expression was higher with lymph node metastasis } \\
(p=0.0005) \text {. }\end{array}$ \\
\hline Liu et $\mathrm{al}^{37}$ & HMGB1 (HNSCC) & $\mathrm{IHC}$ & $\begin{array}{l}\text { - Expressed in } 88.3 \% \text { of primary tumor samples and } 43.7 \% \text { in } \\
\text { adjacent normal tissue }(p<0.001) \text {. } \\
\text { - Correlated with tumor T classification }(p=0.001) \text {, advanced } \\
\text { stage }(p<0.001) \text {, lymph node metastasis }(p<0.001) \\
\text { recurrence }(p<0.001) \text {, disease-free survival }(p<0.001) \text {, } \\
\text { and overall survival }(p<0.001) \text {. } \\
\text { - Was not correlated with age, alcohol intake, smoking, tumor } \\
\text { grade, and tumor site. }\end{array}$ \\
\hline Wild et $\mathrm{al}^{38}$ & HMGB1 (HNSCC) & $\begin{array}{l}\text { IF, real-time } \\
P C R \text {, and ELISA }\end{array}$ & $\begin{array}{l}\text { - Expressed more strongly in tumor tissue than tumor-adjacent } \\
\text { stroma }(p=0.005) \text {. } \\
\text { HMGB1 levels were higher in sera of HNSCC patients than } \\
\text { controls }(p=0.002) \text {. }\end{array}$ \\
\hline Qiu et $\mathrm{al}^{39}$ & HMGB1 (LSCC) & ELISA & $\begin{array}{l}\text { - Associated with T classification }(p=0.005) \text {, N classification } \\
(p=0.002) \text {, and clinical stage }(p=0.001) \text {. } \\
\text { - High HMGB1 (cutoff } 4.80 \mathrm{ng} / \mathrm{mL}) \text { was associated with poorer } \\
\text { overall survival rate }(p=0.036) \text {. } \\
\text { - Diagnosis of LSCC: } 42.0 \% \text { sensitive, } 88.3 \% \text { specific, positive } \\
\text { predictive value of } 52.9 \% \text { (cutoff } 4.80 \mathrm{ng} / \mathrm{mL} \text { ) }\end{array}$ \\
\hline Hanakawa et al ${ }^{40}$ & $\begin{array}{l}\text { HMGB1 } \\
\text { (Tongue SCC) }\end{array}$ & $\mathrm{IHC}$ & $\begin{array}{l}\text { - Expression is not significantly associated with late neck } \\
\text { metastases. }\end{array}$ \\
\hline Supic et al ${ }^{41}$ & HMGB1 (OSCC) & $\begin{array}{l}\text { TaqMan } \\
\text { genotyping }\end{array}$ & $\begin{array}{l}\text { HMGB1 G/C polymorphism analysis: } \\
\text { - } 1177 G G \text { genotype had higher prevalence of advance tumor } \\
\text { stage III ( } p=0.016) \text { and significantly lower RFS ( } p=0.000) \text {. } \\
\text { - 3814CC genotype had higher prevalence of nodal metastasis } \\
\text { and advance tumor stage III }(p=0.019) \text {. }\end{array}$ \\
\hline Su et $\mathrm{al}^{34}$ & RAGE (OSCC) & $\begin{array}{l}\text { TaqMan } \\
\text { genotyping }\end{array}$ & $\begin{array}{l}\text { - -429TC genotype was associated with oral cancer incidence } \\
\text { (OR, 1.870; } 95 \% \mathrm{Cl}, 1.323-2.644 \text { ) and late stage tumors } \\
\text { (OR, } 1.644 ; 95 \% \mathrm{Cl}, 1.083 \text { to } 2.493) \text {. }\end{array}$ \\
\hline
\end{tabular}

Abbreviations: 95\% Cl, 95\% confidence interval; HNSCC, head and neck squamous cell carcinoma; LSCC, laryngeal squamous cell carcinoma; LVD, lymph vessel density; MVD, microvessel density; NPC, nasopharyngeal carcinoma; OR, odds ratio; OSCC, oral squamous cell carcinoma; SCC, squamous cell carcinoma; VEGF, vascular endothelial growth factor. 
classification ( $p=0.002)$, clinical stage $(p=0.001)$, and poorer overall survival rate $(p=0.036)$. The study found no association between serum HMB1 level and gender $(p=0.814)$, age $(p=0.174)$, tumor site $(p=0.733)$, and degree of differentiation $(p=0.727)$. Wild et $\mathrm{a}^{38}$ performed the only other evaluation of serum HGMB1 levels. Sera of 35 HNSCC patients contained significantly higher concentrations of HMGB1 compared with that of controls ( $p=0.002$ ). HMGB1 levels of patients' sera were also analyzed against clinic pathological characteristics of patients (including cancer location, age, sex, therapy, staging, and grading), but they found no significant associations. Further analysis of frozen sections from HNSCC patients demonstrated stronger HMGB1 expression in tumor islands than in tumorsurrounding stroma $(p=0.005)$.

Three studies $35,40,41$ investigated the role of HMGB1 in OSCC. Sasahira et $a^{35}$ analyzed 62 specimens of primary OSCC. HMGB1 was found to be highly expressed in cancer cell nuclei and nodal metastatic foci. Comparison with expression of VEGF-C and VEGF-D demonstrated a significant correlation $(p<0.001)$. Interestingly, analysis of HMGB1 levels in 26 specimens from patients with tongue $\mathrm{SCC}^{40}$ demonstrated no significant association between high HMGB1 expression and late neck metastases. Supic et $\mathrm{al}^{41}$ explored the role of polymorphisms in the HMGB1 gene in OSCC. Using TaqMan genotyping assays, they analyzed four single-nucleotide polymorphisms within the HMGB1 gene in 246 patients: $2262 \mathrm{G}$ $>\mathrm{A} \quad(\mathrm{rs} 1045411), \quad 1177 \mathrm{G}>\mathrm{C} \quad(\mathrm{rs3742305}), \quad 3814 \mathrm{C}>\mathrm{G}$ (rs2249825), and rs4540927. The $1177 \mathrm{G}>\mathrm{C}$ polymorphism was associated with longer recurrence-free survival $(p=0.000$ ), but not overall survival (though a trend was noted of worse survival with the GG phenotype, $p=0.104$ ). Additionally, the $1177 \mathrm{G}>\mathrm{C}$ variation was significantly associated higher histological nucleus grade (wild-type versus combined heterozygote and variant homozygote genotype, $p=0.010)$, nodal metastasis $(p=0.016)$, and higher clinical stage $(p=0.030)$. Additionally, the $3814 \mathrm{C}>\mathrm{G}$ variant was also significantly associated with nodal metastasis (wild-type versus combined heterozygote and variant homozygote genotype, $p=0.019$ ), and higher clinical stage (wild-type versus combined heterozygote and variant homozygote genotype, $p=0.042$ ).

One study analyzed the role of HMGB1 in 166 nasopharyngeal carcinoma specimens from treatment-naive patients. ${ }^{36}$ HMGB1 was detected in $53.6 \%$ of the cases, primarily located in the nuclei and cytoplasm of carcinoma cells and a subset of fibroblasts. HMGB1 was positively correlated with T classification $(p=0.01)$, N classification $(p=0.003)$, distant metastasis $(p=0.046)$, and clinical stage $(p<0.001)$. Additionally, HMGB1 expression correlated significantly with initial radiotherapy response in NPC patients $(p=0.034)$. Prognostically, high HMGB1 expression was associated with a poor overall survival $(p<0.001)$ and disease-free survival $(p<0.001)$. No significant correlation was found between HMGB1 expression and gender, age, pathological classification, or local relapse.

Liu et $\mathrm{al}^{37}$ studied 103 specimens from treatment-naive patients with HNSCC. Tumors were located at superglottic $(N=29)$, glottic $(N=63)$, subglottic $(N=1)$, and hypopharyngeal $(N=10)$ sites. HMGB1 protein was detected in $88.3 \%$ of cases, but only $43.75 \%$ of normal tumor-adjacent tissue controls ( $p<0.001$ ), with higher expression (staining graded as $6-7$ out of 7) in $43.7 \%$ of tumor samples. HMGB1 overexpression was significantly associated with advanced clinical stage, including larger tumor size $(p=0.001)$ and lymph node metastasis $(p<0.001)$, and recurrence $(p<0.001)$. No significant relationship was observed between HMGB1 level and age, alcohol history, smoking, tumor grade, and tumor site. Additionally, high HMGB1 expression was associated with shorter disease-free survival $(p<0.001)$ and overall survival ( $p<0.001)$. HMGB1 was found to be an independent prognostic factor in HNSCC patients after tumor resection (hazard ratio, 2.133; 95\% CI, 1.079-4.218). Further analysis of prognostic value of HMGB1 in patient subgroups demonstrated a high level of HMGB1 expression to be associated with shorter disease-free survival $(p=0.005)$ and overall survival $(p<0.001)$ in late stage group (stage III / IV) patients.

\section{Discussion}

Overall, there was high variation in the included studies, including sample size (range, 20-1210), presence of controls (range, 0 to $1: 1$ ratio), and methodology. The majority of studies included treatment-naive patients, with the exception of one study, ${ }^{41}$ in which neoadjuvant therapy was administered to a fraction of the included patients. Additionally, the total number of investigations is a current limiting factor in determining the true clinical values of HGMB1 and RAGE.

We found no studies that investigate the diagnostic potential of RAGE, while only one study ${ }^{39}$ evaluated the diagnostic value of HMGB1. The low sensitivity of HMGB1 in the diagnosis of LSCC potentially makes HMGB1 a suboptimal marker. However, this study was limited in power $(N=121)$ and by the small sample size of early-stage LSCC patients. Additionally, the multifaceted role of HMB1 and its broad expression likely contribute to its low diagnostic value. Further studies are required to elucidate the diagnostic value of both RAGE and HMGB1, including the possibility of use in conjunction with other markers to improve diagnostic ability.

A total of four studies ${ }^{31-34}$ investigated the prognostic value of RAGE in head and neck cancers (OSCC, $N=3$; nasopharyngeal carcinoma, $N=1$ ). The interaction between HMGB1 and RAGE has been shown to stimulate tumor cell migration and invasion. ${ }^{23}$ Interestingly, Wild et al $^{38}$ found tumor-infiltrating Tregs to express RAGE as well. Further in vitro analysis demonstrated HMGB1 to induce migration of Treg cells isolated from PBMC of patients with HSNCC. This indicates a possible role of tumor-derived HMGB1 in recruitment of Treg cells and, ultimately, suppression of $\mathrm{T}$ cell proliferation within the tumor microenvironment.

According to the available literature reviewed in this article, RAGE appears to be a potential clinical indicator of tumor angiogenesis, differentiation, and staging. Two of the four studies determined RAGE to be correlated with angiogenesis, including tumor microvessel density ${ }^{31,33}$ and VEGF expression. ${ }^{31}$ While some inconsistencies among the studies existed, likely due to variation in study methodology, generally RAGE was correlated with some component of staging. ${ }^{31,33,34}$ Additionally, the 
analysis on polymorphisms in the RAGE gene $\mathrm{e}^{34}$ may indicate the variants to be involved in tumor cell proliferation but not invasion and differentiation. Perhaps some potential exists for the polymorphisms to be used in assessment of risk. Larger studies are required to determine if RAGE is a clinically useful predictor of survival, and further confirm its prognostic value.

Substantial evidence support the association of HMGB1 with clinic pathological characteristics of patients with head and neck cancers, including tumor angiogenesis and staging. Three of the seven studies investigating HMGB1 found high protein expression to be significantly associated with lower overall survival. ${ }^{36,37,39}$ Interestingly, Wu et $\mathrm{al}^{36}$ found high HMGB1 in late-stage nasopharyngeal carcinoma patients (i.e., stages III / IV), to be associated with significantly shorter overall survival when compared with patients with a low level of HMGB1 expression. Conversely, Hanakawa et al ${ }^{40}$ found HMGB1 to not be significantly associated with late neck metastasis in tongue SCC. This is suggestive of HMGB1 possibly being more valuable in determining the prognosis for late-stage patients.

Furthermore, use of HMGB1 in combination with other clinic pathological indicators could improve the prognostic utility. Liu et $\mathrm{al}^{37}$ found the subset of patients with both high HMGB1 expression and positive lymph node metastasis had an even poorer disease-free survival $(p<0.001)$ and overall survival $(p<0.001)$ than that of others.

\section{Final Comments}

The diagnostic value of HMGB1 in head and neck cancer, while not exhaustively investigated, may suffer from low sensitivity. No studies were found to evaluate the diagnostic value of RAGE. The demonstrated associations of HMGB1 and RAGE with clinic pathological characteristics of head and neck cancer patients offer a strong basis for further investigation into the prognostic value of both of these molecules. Early investigation has demonstrated HMGB1 to have definite potential as a predictor for survival, while RAGE has not been as extensively evaluated. Further studies are needed to confirm the clinical prognostic utility of both RAGE and HMGB1.

\section{Acknowledgment}

This work was supported by research grant R01 HL116042 to DK Agrawal from the National Heart, Lung, and Blood Institute, NIH USA.

\section{References}

1 Czura CJ, Wang H, Tracey KJ. Dual roles for HMGB1: DNA binding and cytokine. J Endotoxin Res 2001;7(4):315-321

2 Cheng BQ Jia CQ Liu CT, et al. Serum high mobility group box chromosomal protein 1 is associated with clinicopathologic features in patients with hepatocellular carcinoma. Dig Liver Dis 2008;40(6):446-452

3 Lee $\mathrm{H}$, Song $\mathrm{M}$, Shin $\mathrm{N}$, et al. Diagnostic significance of serum HMGB1 in colorectal carcinomas. PLoS ONE 2012;7(4):e34318
4 Goodwin GH, Sanders C, Johns EW. A new group of chromatinassociated proteins with a high content of acidic and basic amino acids. Eur J Biochem 1973;38(1):14-19

5 Pallier C, Scaffidi P, Chopineau-Proust S, et al. Association of chromatin proteins high mobility group box (HMGB) 1 and HMGB2 with mitotic chromosomes. Mol Biol Cell 2003;14(8): 3414-3426

6 Lotze MT, Tracey KJ. High-mobility group box 1 protein (HMGB1): nuclear weapon in the immune arsenal. Nat Rev Immunol 2005; 5(4):331-342

7 Zhang Z, Wang M, Zhou L, et al. Increased HMGB1 and cleaved caspase- 3 stimulate the proliferation of tumor cells and are correlated with the poor prognosis in colorectal cancer. J Exp Clin Cancer Res 2015;34(1):51-60

8 Evans A, Lennard TW, Davies BR. High-mobility group protein 1 (Y): metastasis-associated or metastasis-inducing? J Surg Oncol 2004;88(2):86-99

9 Palumbo R, Sampaolesi M, De Marchis F, et al. Extracellular HMGB1, a signal of tissue damage, induces mesoangioblast migration and proliferation. J Cell Biol 2004;164(3):441-449

10 Wang H, Yang H, Tracey KJ. Extracellular role of HMGB1 in inflammation and sepsis. J Intern Med 2004;255(3):320-331

11 Hori O, Brett J, Slattery T, et al. The receptor for advanced glycation end products (RAGE) is a cellular binding site for amphoterin. Mediation of neurite outgrowth and co-expression of rage and amphoterin in the developing nervous system. J Biol Chem 1995; 270(43):25752-25761

12 Nguyen AH, Berim IG, Agrawal DK. Chronic inflammation and cancer: emerging roles of triggering receptors expressed on myeloid cells. Expert Rev Clin Immunol 2015;11(7):849-857

13 Chuah YK, Basir R, Talib H, Tie TH, Nordin N. Receptor for advanced glycation end products and its involvement in inflammatory diseases. Int J Inflamm 2013;2013:403460

14 Schlueter C, Weber H, Meyer B, et al. Angiogenetic signaling through hypoxia: HMGB1: an angiogenetic switch molecule. Am J Pathol 2005;166(4):1259-1263

15 Srinivasan M, Banerjee S, Palmer A, et al. HMGB1 in hormonerelated cancer: a potential therapeutic target. Horm Cancer 2014; 5(3):127-139

16 Diener KR, Al-Dasooqi N, Lousberg EL, Hayball JD. The multifunctional alarmin HMGB1 with roles in the pathophysiology of sepsis and cancer. Immunol Cell Biol 2013;91(7):443-450

17 Sasahira T, Sasaki T, Kuniyasu H. Interleukin-15 and transforming growth factor alpha are associated with depletion of tumorassociated macrophages in colon cancer. J Exp Clin Cancer Res 2005;24(1):69-74

18 Luo Y, Chihara Y, Fujimoto K, et al. High mobility group box 1 released from necrotic cells enhances regrowth and metastasis of cancer cells that have survived chemotherapy. Eur J Cancer 2013;49(3):741-751

19 Kang R, Tang D, Schapiro NE, et al. The receptor for advanced glycation end products (RAGE) sustains autophagy and limits apoptosis, promoting pancreatic tumor cell survival. Cell Death Differ 2010;17(4):666-676

20 Taguchi A, Blood DC, del Toro G, et al. Blockade of RAGE-amphoterin signalling suppresses tumour growth and metastases. Nature 2000;405(6784):354-360

21 Campana L, Bosurgi L, Rovere-Querini P. HMGB1: a two-headed signal regulating tumor progression and immunity. Curr Opin Immunol 2008;20(5):518-523

22 Ellerman JE, Brown CK, de Vera M, et al. Masquerader: high mobility group box-1 and cancer. Clin Cancer Res 2007;13(10): 2836-2848

23 Kang R, Zhang Q Zeh HJ III, Lotze MT, Tang D. HMGB1 in cancer: good, bad, or both? Clin Cancer Res 2013;19(15):4046-4057

24 Tang D, Kang R, Zeh HJ III, Lotze MT. High-mobility group box 1 and cancer. Biochim Biophys Acta 2010;1799(1-2):131-140

25 Kuniyasu H, Chihara Y, Kondo H, Ohmori H, Ukai R. Amphoterin induction in prostatic stromal cells by androgen deprivation is 
associated with metastatic prostate cancer. Oncol Rep 2003;10(6): 1863-1868

26 Tarbé N, Evtimova V, Burtscher H, Jarsch M, Alves F, Weidle UH. Transcriptional profiling of cell lines derived from an orthotopic pancreatic tumor model reveals metastasis-associated genes. Anticancer Res 2001;21(5):3221-3228

27 Maeda S, Hikiba Y, Shibata W, et al. Essential roles of high-mobility group box 1 in the development of murine colitis and colitisassociated cancer. Biochem Biophys Res Commun 2007;360(2): 394-400

28 Leman ES, Madigan MC, Brünagel G, Takaha N, Coffey DS, Getzenberg RH. Nuclear matrix localization of high mobility group protein $\mathrm{I}(\mathrm{Y})$ in a transgenic mouse model for prostate cancer. J Cell Biochem 2003;88(3):599-608

29 Dolde CE, Mukherjee M, Cho C, Resar LM. HMG-I/Y in human breast cancer cell lines. Breast Cancer Res Treat 2002;71(3): 181-191

30 Siegel RL, Miller KD, Jemal A. Cancer statistics, 2015. CA Cancer J Clin 2015;65(1):5-29

31 Sasahira T, Kirita T, Bhawal UK, et al. The expression of receptor for advanced glycation end products is associated with angiogenesis in human oral squamous cell carcinoma. Virchows Arch 2007; 450(3):287-295

32 Landesberg R, Woo V, Huang L, et al. The expression of the receptor for glycation endproducts (RAGE) in oral squamous cell carcinomas. Oral Surg Oral Med Oral Pathol Oral Radiol Endod 2008; 105(5):617-624

33 Tsuji A, Wakisaka N, Kondo S, Murono S, Furukawa M, Yoshizaki T. Induction of receptor for advanced glycation end products by EBV latent membrane protein 1 and its correlation with angiogenesis and cervical lymph node metastasis in nasopharyngeal carcinoma. Clin Cancer Res 2008;14(17):5368-5375

34 Su S, Chien M, Lin C, Chen M, Yang S. RAGE gene polymorphism and environmental factor in the risk of oral cancer. J Dent Res 2015; 94(3):403-411

35 Sasahira T, Kirita T, Oue N, et al. High mobility group box-1inducible melanoma inhibitory activity is associated with nodal metastasis and lymphangiogenesis in oral squamous cell carcinoma. Cancer Sci 2008;99(9):1806-1812

36 Wu D, Ding Y, Wang S, Zhang Q, Liu L. Increased expression of high mobility group box 1 (HMGB1) is associated with progression and poor prognosis in human nasopharyngeal carcinoma. J Pathol 2008;216(2):167-175

37 Liu Y, Xie C, Zhang X, et al. Elevated expression of HMGB1 in squamous-cell carcinoma of the head and neck and its clinical significance. Eur J Cancer 2010;46(16):3007-3015

38 Wild CA, Brandau S, Lotfi R, et al. HMGB1 is overexpressed in tumor cells and promotes activity of regulatory $T$ cells in patients with head and neck cancer. Oral Oncol 2012;48(5):409-416

39 Qiu G, Li Y, Liu Z, Wang M, Ge J, Bai X. Clinical value of serum HMGB1 in diagnosis and prognosis of laryngeal squamous cell carcinoma. Med Oncol 2014;31(12):316

40 Hanakawa H, Orita Y, Sato Y, et al. Does HMGB1 predict occult neck lymph node metastasis in early tongue carcinoma? A case-control study of 26 patients. J Laryngol Otol 2014;128(10):926-931

41 Supic G, Kozomara R, Zeljic K, et al. HMGB1 genetic polymorphisms in oral squamous cell carcinoma and oral lichen planus patients. Oral Dis 2015;21(4):536-543 